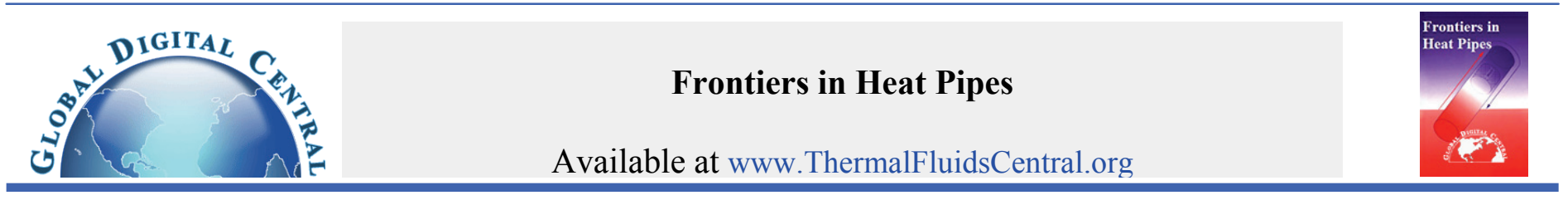

\title{
INVESTIGATION OF THE THERMAL PERFORMANCE CHARACTERISTICS OF A VARIABLE CONDUCTANCE ARTERIAL HEAT PIPE
}

\author{
Tarik Kaya $^{\mathrm{a},{ }^{*}}$ and Konstantin Goncharov ${ }^{\mathrm{b}}$ \\ ${ }^{a}$ Carleton University, Department of Mechanical and Aerospace Engineering, 1125 Colonel By Drive, Ottawa, Ontario K1S 5B6, Canada \\ ${ }^{b}$ TAIS Ltd., Fabrichnaja 8, Pravdinsky, Moscow reg. 141260, Russia
}

\begin{abstract}
A single-artery variable conductance arterial heat pipe was experimentally and numerically studied. To investigate the growth of the noncondensible gas supported bubbles, one-dimensional time-dependent conservation equations were solved by using the finite element method. It was shown that the time of collapse for the diffusion-controlled bubbles was relatively short in the condenser. However, the bubbles grew very rapidly in the evaporator even at moderate superheat levels, which demonstrated that the heat pipe would experience arterial blockage and subsequent dryout without vapor venting pores. An optimum diameter and spacing for the venting pores were calculated to maximize the heat transfer limit and minimize the pressure drop. Test results demonstrated heat load limits up to $120 \mathrm{~W}$ and a narrow temperature control range.
\end{abstract}

Keywords: arterial heat pipes, variable conductance heat pipes, meniscus coalescence

\section{INTRODUCTION}

The thermal control of modern electronics equipment in space and ground applications is becoming more and more demanding in terms of the need to provide higher heat rejection capability, a narrower temperature range and flexible transport sections. Therefore, there is an increasing interest in arterial heat pipes (AHPs), which were first introduced in the 1970's. In an AHP, the viscous losses are minimized by using separate fluid flow passages or arteries in combination with fine capillary structures. As a result, it is possible to increase the available capillary pressure without excessively decreasing the permeability of the capillary structure. An AHP can also be manufactured easily with flexible sections and rigid bends. The main motivation for this work is to provide thermal control for applications with high heat load and precise temperature control requirements.

Based on the separate fluid flow passage principle, several different and highly innovative AHP designs have been proposed in the past. However, many of these AHP designs were abandoned as a result of startup failures and dryout experienced during their operation. This was mainly due to the fact that in an AHP the fine mesh wick used to form the artery wets more rapidly than the artery can selfprime. As a result, the vapor partially or completely impedes the arterial flow, leading to arterial dryout. This phenomenon is referred as the glazing effect (Eninger, 1974). A review of the most important AHP designs and some of the failure mechanisms will be discussed next.

The two earliest and notable AHPs were the pedestal and spiral artery designs. These configurations were flight tested aboard sounding rockets (McIntosh et al., 1972 and 1975) and were also flown on the Orbital Astronomical Observatory (OAO-C) spacecraft along with another arterial design (Wanous et al., 1975). Ammonia was used as working fluid in both of the pipes. In the pedestal AHP, a circular crosssection artery was connected to the pipe wall by two retainer legs fabricated from stainless-steel mesh. The pedestal AHP was manufactured using aluminum tubing with circumferential screw grooves on the inside surface. The artery was offset from the pipe center to assist selfpriming under gravity. The pedestal artery was difficult to prime because of its sensitivity to the gas bubbles in the arteries. They had to be overcharged to induce priming. For the spiral AHP, aluminum tubing with internal circumferential grooves was also used. To form the artery, a stainless-steel screen mesh was rolled with successive gaps around a central rod. The spiral artery was connected to the pipe wall by a three-legged stainless-steel screen retainer. The spiral artery design was selfpriming. However, because of the low vapor/liquid volume ratio, it was susceptible to condenser blockage by excess liquid. Therefore, their charge had to be very accurate. The noncondensible gas (NCG) tolerance was low due to the potential condenser blockage. In addition to these two AHP designs, the OAO spacecraft contained a gas controlled, variable conductance heat pipe with stainless-steel mesh kidney-shaped artery with a hot and nonwicked reservoir. Methanol was the working fluid and helium was used as control gas. In spite of the limited telemetry, the OAO flight data have proven the successful operation of all these arterial pipes in microgravity.

An interesting AHP design was used to cool the traveling wave tube amplifiers aboard the Communication Technology Satellite (CTS) (Mock et al., 1975). These AHPs had two circular cross-section arteries fabricated from stainless-steel mesh. These two arteries were spot welded to a felt-metal bridge wick. This bridge wick provided the liquid flow to the circumferential wall grooves from the circular arteries. A

\footnotetext{
*Corresponding author.Email: tkaya@mae.carleton.ca
} 
separate priming foil as suggested in (Eninger, 1974), which will be discussed in detail later, was incorporated into the artery. The CTS pipes used methanol as the working fluid instead of more efficient ammonia. It was decided that the combination of low superheat, high $\left(d P_{s a t} / d T\right)$ and high vapor pressure of ammonia would increase the risk of arterial deprime (Saaski, 1972). A mixture of 90\% nitrogen and 10\% helium was used to control the pipe operation. Helium was introduced for leak detection. The CTS AHPs were deprimed four times in orbit. An elaborate experimental investigation on the ground showed that the freeze/thaw cycle of the working fluid resulted in separation of the working fluid and control gas, leading to formation of small bubbles (Antonuik and Edwards, 1980). As a result, it was recommended that the freezing of the heat pipe working fluid should be avoided.

In Europe, AHPs were also developed in the same period. The most notable one was the Institut for Kernenergetik's (IKE) 8-shaped artery heat pipe design, consisting of two large annular arteries in contact with a circumferential screen lining the interior wall of the heat pipe. Each large artery encircled two smaller arteries. This design was used in the ESA's MARECS maritime communication satellites. A liquid-trap diode heat pipe based on this arterial design was also tested on board Space Shuttle (Supper and Groll, 1985). In Abhat et al. (1975), a modular artery design using the same concept was analyzed. In this design, a large outer artery enclosed three smaller enclosure arteries, each surrounding six smaller arteries. The authors reported that the nucleation within the artery was the main reason for the performance deterioration of the AHP and the design was based on this belief. The liquid in smaller arteries being far away from the vapor space was less susceptible to nucleation and they had a higher chance of being well-primed during the pipe operation.

Alario et al. (1981) developed the monogroove AHP, where the liquid artery was a single axial reentrant groove connected to the vapor channel through a narrow channel. The vapor space contained circumferential wall grooves. The capillary pumping pressure was provided within the narrow longitudinal channel. Because of the latter, the liquid charge in a monogroove heat pipe was found to be extremely critical. Venting of NCG-supported bubbles through this narrow slot was also difficult as it was observed during the SHARE space flight experiment (Kosson et al., 1990). The monogroove design was later modified to avoid these problems: a screen wick was added to the evaporator section to provide liquid to the wall grooves during an arterial blockage; a larger slot with a channel splitter was introduced to help easily venting the NCG-supported vapor bubbles (Ambrose and Holmes, 1991); and an electrohydrodynamic pump was used to provide quick recovery from dryout (Bryan and Seyed-Yagoobi, 1997). The development of monogroove heat pipe was later abandoned due to operational problems associated with premature evaporator dryout during startup and transients.

The tapered AHP proposed in (Holmes and Field, 1986) combines the monogroove concept and meniscus coalescence method to vent the NCG-supported bubbles through a self adjusting mechanism. This heat pipe had a similar cross section to the monogroove heat pipe except that the liquid artery was tapered. If a bubble forms and eventually expands in the liquid artery, the circumferential wall grooves in the evaporator section will begin to dry out. This in turn causes the slot meniscus to recede towards the artery. Later, the receding slot meniscus and meniscus of the growing bubble due to the reduced wall groove evaporation rate coalesce, leading to venting of the bubble to the vapor space. The bubble venting mechanism was successfully demonstrated during the ground tests. However, no microgravity demonstration was carried out later.

Two other interesting AHP designs are the self-filling AHP and Double Wall Artery Heat Pipe (DWAHP). The self-filling hallow core AHP, developed by Kosson and Swerdling (1975), consisted of several layers of fine screen layers wrapped around a large flow channel (tunnel), supported in the center of a circumferentially grooved pipe. The fine screen layers were sized to self-prime by surface tension. The pressure priming technique was used to ensure that any vapor bubbles within the capillary passages were collapsed, leading to the tunnel to be completely liquid filled. Pressure priming also provided the necessary pressure differential to accelerate the collapse of NCG by mass diffusion. DWAHP used an internal tube with external axial grooves (arteries), an external tube with internal circumferential grooves, and a screen-mesh wick in the middle (Ponnappan et al., 1986). All these elements were packaged in a single concentric assembly. The artery blockage by vapor injection from the evaporator to the arteries was also problematic, which was later modified by using short capillary inserts in the arteries (Ponnappan et al., 1988).

A miniature AHP design was also proposed by Maziuk (2005). The miniature AHP looks like a classical heat pipe with a circumferential sintered powder wick except a small liquid artery separated from the vapor space by a thin copper plate. The important feature of this design is that the artery is continuous in the condenser and adiabatic regions, but it ends just before the evaporation region by joining to the sintered annular wick. This reduces the risk of formation of vapor bubbles in the liquid artery. It was demonstrated that a 4-mm outer diameter copper-water heat pipe can carry up to $16 \mathrm{Wm}$.

More recently, a flexible high-performance variable conductance AHP was also presented by Streckert and Ambrose (2009). The pipe had a single liquid passage through most of its length. It also included two flexible sections and multiple bends. The design was based on the graded single groove heat pipe previously developed by (Ambrose and Holmes, 1991). The steady-state and transient response of this pipe were presented and it was demonstrated that the AHP can carry a heat flux of more than $50 \mathrm{~W} / \mathrm{cm}^{2}$ and the maximum heat transport limit was $150 \mathrm{Wm}$ for a $1-\mathrm{cm}$ outer diameter pipe.

A summary of additional AHP designs can be found in Faghri (1995) and Schlitt (1997).

In this work, a unique single-artery variable conductance AHP (VCAHP) design developed by Goncharov et al. (2000) based on an earlier design by Blinchevskii et al. (1983) in Russia was studied. The pipe conductance is controlled by using an NCG (nitrogen) and gas reservoir, which is directly attached to the end of the condenser. The details of the heat pipe design are explained in the following section. This paper presents the experimental results and analysis for this unique VCAHP. The main objective of this work is to demonstrate the variable conductance operation by test results and analyze the bubble behavior in the artery to optimize some of the important design parameters of the VCAHP.

\section{EXPERIMENTAL ANALYSIS}

\subsection{Experimental Setup}

The VCAHP investigated in this work is shown in Fig. 1. The pipe is made of a stainless steel tube with an outer diameter of $12.2 \mathrm{~mm}$ and wall thickness of $0.5 \mathrm{~mm}$. The working fluid is the high purity ammonia. The condenser and adiabatic sections are bonded through an L-shape connector. A single artery, as shown in the pipe cross section C-C in Fig. 1, is formed using a stainless steel mesh of 680 wires per inch. The height and width of the artery are $1.5 \mathrm{~mm}$ and $7.63 \mathrm{~mm}$, respectively. The artery is connected to the inner wall of the pipe body and serves as liquid transportation medium from condenser to evaporator. The artery is also bonded through the L-shape connector. An important design feature of the pipe is the vapor venting pores. They are positioned along the artery mesh in the evaporator section. When the artery is blocked by vapor, the menisci formed on the opposite sides of the liquid in a venting pore merge and the artery primes. This will be discussed in detail later in the article.

Circumferential screw grooves on the inside wall are manufactured along the entire pipe length with a depth of $0.15 \mathrm{~mm}$ and a width of $0.1 \mathrm{~mm}$. The circumferential grooves provide a large thin film for evaporation, which helps prevent boiling in the liquid artery. They also transport liquid from the liquid artery along the perimeter of 
the heat pipe. As the vapor flow and liquid flow are separated by the arterial screen mesh, there is no constraint due to the entrainment.
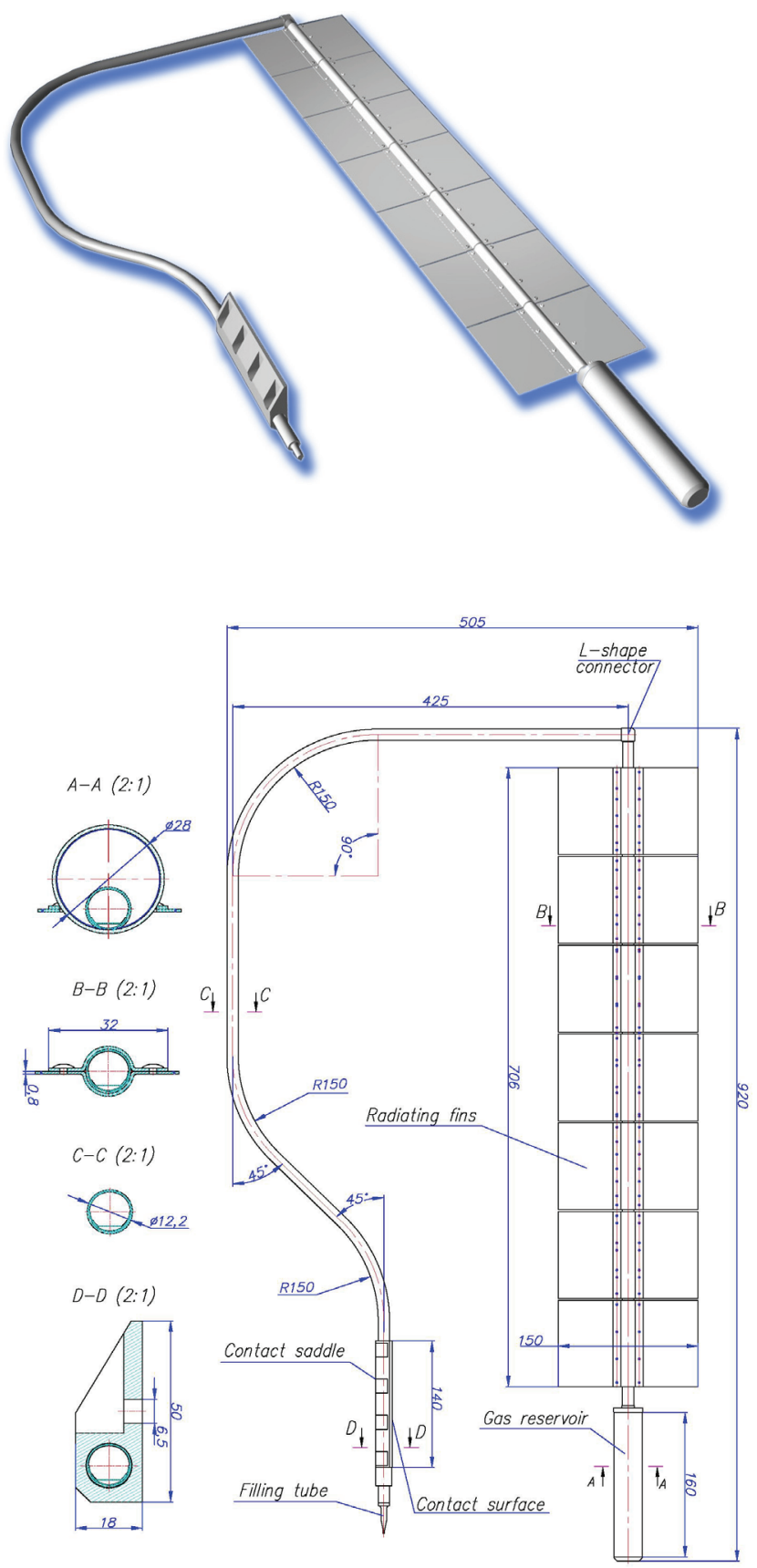

Fig. 1 Picture and overall dimensions of VCAHP.

Based on the same design, low-temperature, diode and flexible heat pipes were also manufactured and successfully implemented for the Oko-1 family spacecraft (Goncharov et al. 2006).

A gas-controlled heat pipe is different from a conventional AHP mainly because of the presence of a gas reservoir. The gas reservoir is made from stainless steel tube with an outer diameter of $28 \mathrm{~mm}$. It is filled with nitrogen to control the pipe conductance. The filling tube is welded to one end of the pipe body and it is used to fill the pipe with working fluid and nitrogen. The L-shape connector allows bending the parts of the body and artery at right angles without the need for a bending radius, while keeping the continuity of the artery.
The heat is applied through an aluminum saddle soldered to the evaporator as shown in Fig. 1. Radiating fins made from aluminum sheet are attached to the condenser using thermally conductive glue.

The main characteristics of the VCAHP are given in Table 1.

Table 1 Main characteristics of VCAHP.

\begin{tabular}{|l|r|}
\hline Outer diameter $(\mathrm{mm})$ & 12.2 \\
\hline Length of evaporator $(\mathrm{mm})$ & 141.0 \\
\hline Length of condenser $(\mathrm{mm})$ & 700.0 \\
\hline Total length $(\mathrm{mm})$ & 2065.0 \\
\hline Width of evaporator saddle $(\mathrm{mm})$ & 50.0 \\
\hline Width of radiating fins $(\mathrm{mm})$ & 150.0 \\
\hline Volume of gas reservoir $\left(\mathrm{cm}^{3}\right)$ & 100.0 \\
\hline Mass of ammonia $(\mathrm{g})$ & 25.0 \\
\hline Mass of nitrogen $(\mathrm{g})$ & 1.6 \\
\hline Total mass $(\mathrm{g})$ & 1100.0 \\
\hline
\end{tabular}

The tests were carried out in a vacuum chamber, which used a shroud cooled by the liquid nitrogen. The heat pipe was maintained in a horizontal position inside the vacuum chamber. The pipe was mounted on a rotating table through risers. The film heaters were mounted to the evaporator saddle and a graphite film was used as interfiller. The cooling was provided by radiation heat transfer between the pipe radiating fins and chamber shroud. Sink temperature was measured by two heat flow sensors mounted near the condenser. The evaporator, adiabatic section and gas reservoir were separately insulated with multilayer insulation (MLI). Twenty T-type thermocouples were positioned on the heat pipe as shown in Fig. 2. Thermocouples on the adiabatic section and condenser were mounted in pairs: one thermocouple on the vapor zone, another on the surface just underneath the artery.

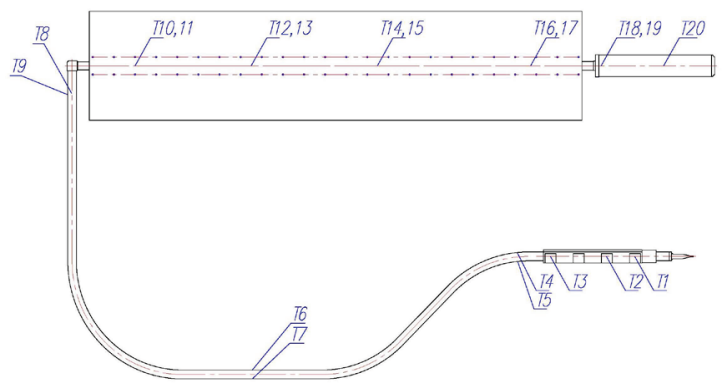

Fig. 2 Thermocouple locations.

\subsection{Test Results}

A typical power cycle test of the VCAHP is shown in Fig. 3. For clarity, in the figures, only the results from a selected set of thermocouples were presented: mid-evaporator, mid-adiabatic section (vapor side) and four condenser thermocouples (vapor side), midreservoir and average shroud.

The purpose of the first test was the determination of the maximum heat transport capability of the heat pipe. The cooling of the shroud was first initiated and all the temperatures started dropping as shown in Fig. 3. Later, a startup power of $30 \mathrm{~W}$ was applied to the pipe and the pipe immediately started. The temperatures continued to drop as the shroud temperature was continuously decreasing. The gas front was positioned between T14 and T16 following the startup, but later it moved up to between T12 and T14 until the next power was applied as shown in Fig. 3. Then, the power was increased in steps. At $100 \mathrm{~W}$, the pipe showed the early signs of the heat transport limit as the evaporator thermal resistance started increasing. When a higher heat load of $120 \mathrm{~W}$ was applied, it was clear that the heat transport limit was reached. 


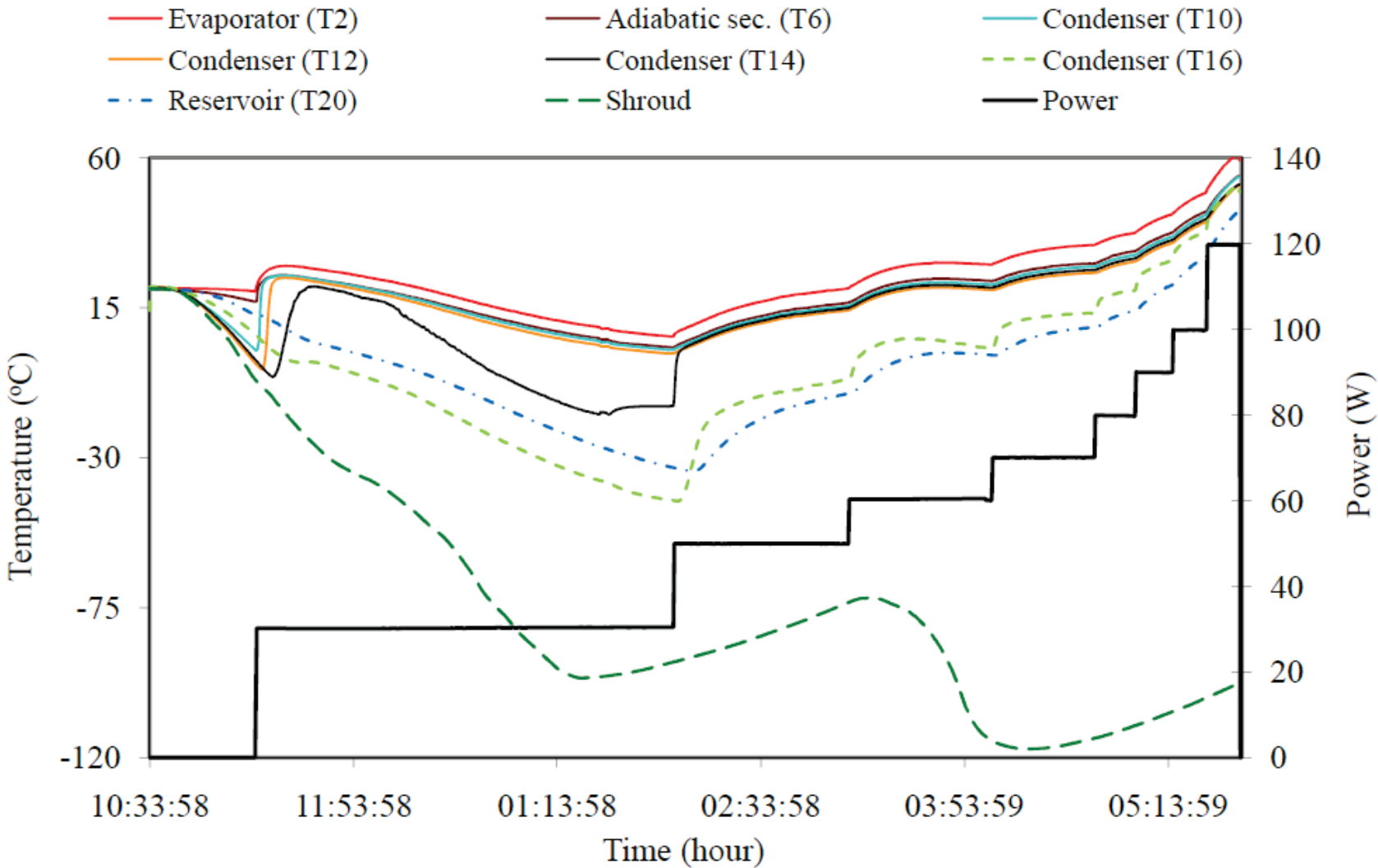

Fig. 3 Temperature profiles for the heat transfer limit test.

- Evaporator (T2)

Condenser (T12)

-. - Reservoir (T20)
- Adiabatic sec. (T6)

Condenser (T14)

- - Shroud
- Condenser (T10)

- - - Condenser (T16)

- Power

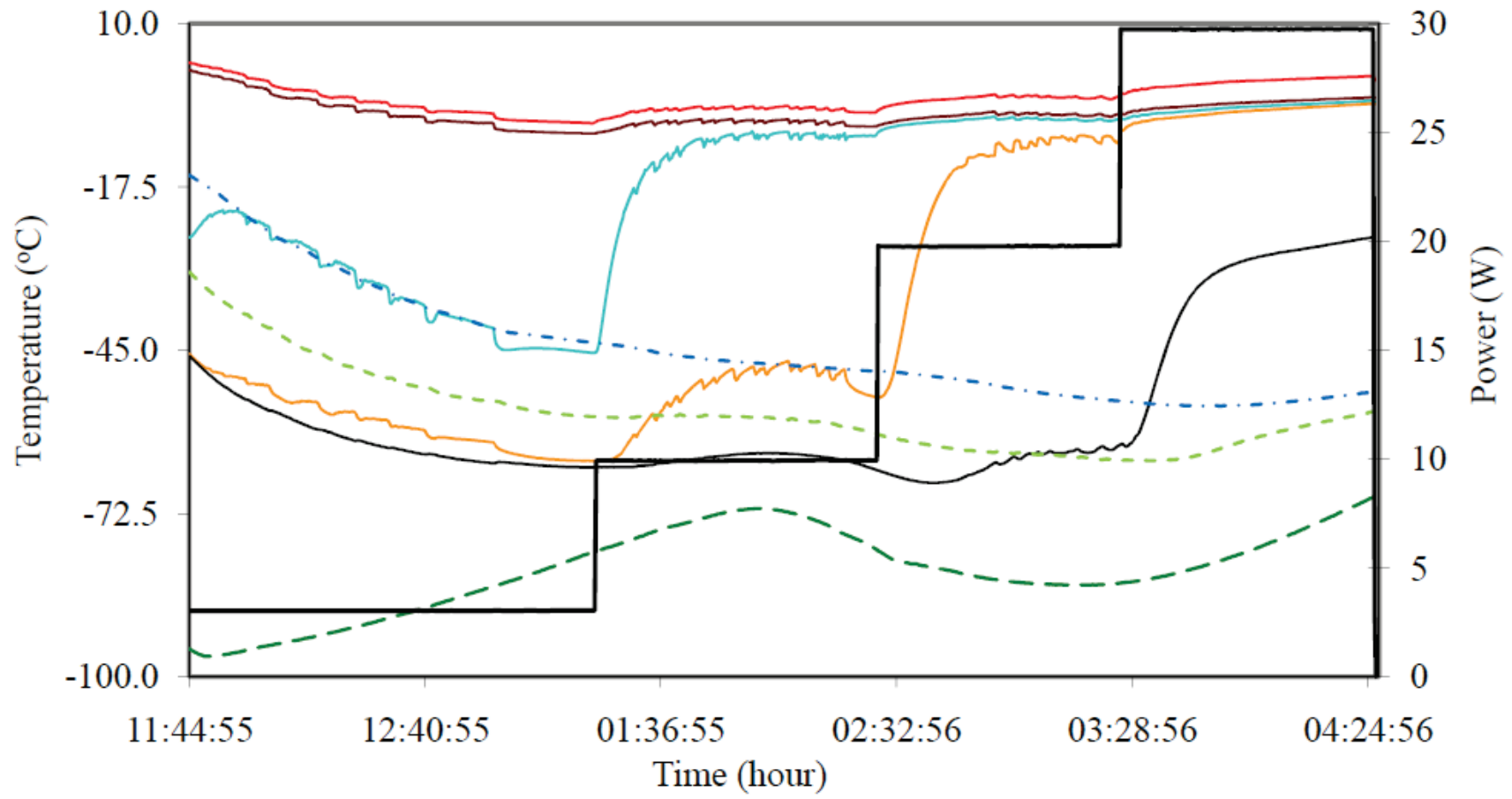

Fig. 4 Temperature profiles for the variable conductance operation test. 
Figure 4 shows a typical test demonstrating the variable conductance operation of the heat pipe. The control gas in the gas reservoir blocks part of the condenser length depending on the operating condition. In doing so, it prevents vapor condensation in the blocked part of the condenser. When the heat load increases, the vapor pressure increases and the control gas is compressed, which in turn opens up more condenser area. As a result, the pipe operating temperature can be maintained within a defined temperature range in spite of the change in applied power. The presence of the control gas also provides a sufficient diode action since when the direction of the heat flow changes, the gas moves towards the evaporator, obstructing the heat transfer.

For the variable conductance test, the heat pipe was started with a low startup power of $3 \mathrm{~W}$. The shroud temperature fluctuated between $-96^{\circ} \mathrm{C}$ and $-70^{\circ} \mathrm{C}$. The power was increased in steps up to $30 \mathrm{~W}$. The progression of the gas front is easy to follow on Fig. 4 by noticing the sudden increase of the condenser thermocouples in sequence at each power setting. More importantly, the variable conductance operation is clearly noticeable. The temperature regulation range was within $12^{\circ} \mathrm{C}$ (between $-8.5^{\circ} \mathrm{C}$ and $3{ }^{\circ} \mathrm{C}$ ) when the power was varied from 3 to $30 \mathrm{~W}$ and the sink from -96 to $-70^{\circ} \mathrm{C}$.

\section{NUMERICAL AND ANALYTICAL ANALYSIS}

\subsection{Vapor-Gas Bubbles}

As it was previously mentioned, nitrogen was introduced to into the VCAHP to control the conductance. In addition to the inevitable presence of the NCGs (unintentionally introduced during the manufacturing or generated over the life time by chemical reactions) in the heat pipe, the presence of the control gas makes the heat pipe more susceptible to the arterial blockage. NCG can facilitate the bubble formation in the liquid artery through several mechanisms. In practice, the most important mechanisms are a sudden power increase and a rapid decrease in sink temperature. Following a sudden power increase, the partial pressure of NCGs will decrease and NCGs will be likely to come out of the liquid in the artery. This will result in the formation of the NCG-supported bubbles in the condenser. Alternatively, a sudden power increase may lead to vapor bubble formation due to the resulting superheated liquid at the arterial wall in the evaporator. In a similar way, a rapid decrease in the sink temperature may cause flash boiling at the artery wall in the condenser if the superheat is sufficiently large. The vapor-gas bubbles, regardless of the location of their formation, will be swept towards the evaporator. If these bubbles are small, they may not cause an arterial blockage. However, sufficiently large bubbles may merge together and block the artery.

The behavior of the NCG-supported bubbles formed in the condenser was studied in Kaya (2009). A numerical analysis was performed for a spherical bubble consisting of the ammonia vapor and NCGs including the control gas. The molar fractions of the NCG $\left(\mathrm{H}_{2}\right.$ and $\mathrm{N}_{2}$ ) generated due to the ammonia decomposition were calculated for a 20 year life time using the Arrhenius equation. The mass diffusion equation together with the conservation of mass and momentum equations were solved for the multicomponent mixture. The details of the boundary conditions and solution procedure were explained in Kaya (2009); therefore, it is not repeated here. This analysis demonstrated that the NCG-supported bubbles in the condenser were absorbed relatively fast. The collapse time increased quickly at low temperatures mainly due to the decreasing solubility of hydrogen with temperature. Typical results obtained for the VCAHP studied here is shown in Fig. 5, where the bubbles are assumed as collapsed when the bubble radius reaches $1 / 10^{\text {th }}$ of its initial radius. In Fig. 5, the bubble radius is nondimensionalized with the initial bubble radius. The lifetimes of a $100 \mu \mathrm{m}$ bubble was calculated for the four different sink temperatures. The bubbles reabsorbed slower with the decreasing sink temperatures. The time of reabsorption increased more than four times when the sink temperature was decreased from $293 \mathrm{~K}$ to $233 \mathrm{~K}$. The reabsorbtion time also increased with the increasing bubble initial radius. For example, for an initial radius of $400 \mu \mathrm{m}$, the bubble collapsed after $488.7 \mathrm{~s}$ at $269 \mathrm{~K}$.

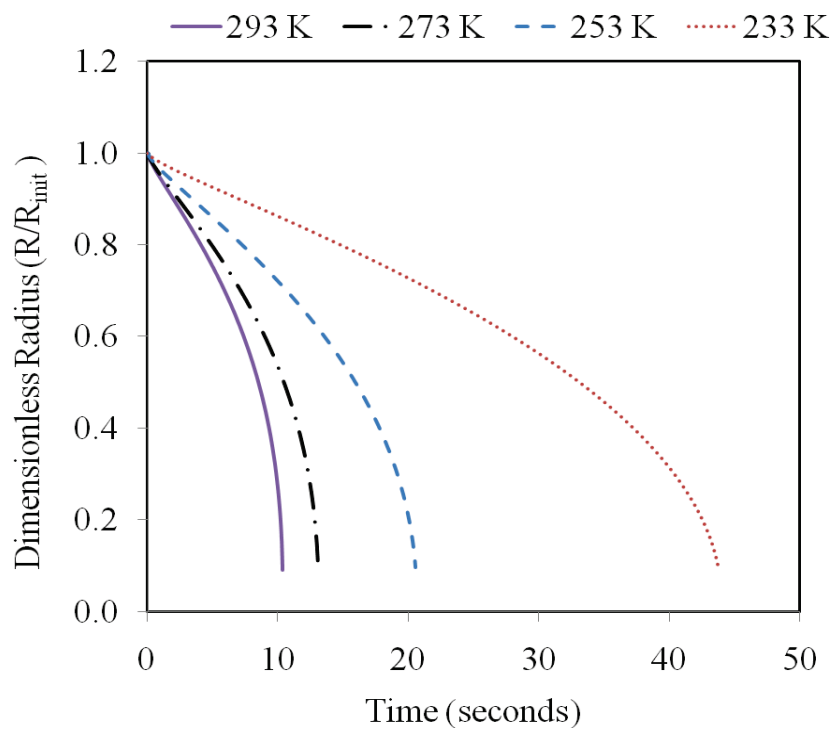

Fig. 5 Bubble collapse time at different sink temperatures.

As the bubbles can survive for a long time especially at low temperatures, an arterial deprime resulting from the merging of the NCG-supported bubbles is very likely. When the artery is blocked, the evaporator will dry out. A partial blockage of the artery will reduce the arterial permeability. Depending on the size of the blockage, an evaporator dryout may also occur due to the insufficient amount of returning liquid. Following the dryout, the arterial blockage will most likely continue to grow into an elongated bubble until it reaches the evaporator. Then, limiting the vapor venting pores only to the evaporator section will be a good design option to minimize the pressure drop introduced by these pores without jeopardizing the arterial reprime capability.

As a result, the behavior of the vapor-gas bubbles in the evaporator section needs to be carefully investigated. In addition to the convection of the bubbles formed in the condenser with the arterial liquid flow to the evaporator, the bubbles can also be formed inside the artery in the evaporator due to a sudden power increase. To calculate the growth rate of these bubbles regardless of their origin, a numerical model was developed. In this model, a spherical bubble was considered. As the diffusion-controlled bubble growth is much slower than the bubble growth due to the evaporation, a simultaneous solution of the mass and thermal diffusion equations is not required.

The conservation of mass, momentum and energy equations for a spherical bubble take the following form

$u_{r}=\varepsilon\left(\frac{R}{r}\right)^{2} \frac{d R}{d t}$

where ${ }_{\varepsilon}=1-\frac{\rho_{v}}{\rho_{\ell}}$

$R \frac{d^{2} R}{d t^{2}}+\frac{3}{2}\left(\frac{d R}{d t}\right)^{2}=\frac{P_{\mathrm{v}}(T)-P_{\infty}}{\varepsilon \rho_{\ell}}-\frac{2 \sigma(T)}{\varepsilon \rho_{\ell} R}-\frac{4 \mu_{\ell}}{\varepsilon \rho_{\ell} R} \frac{d R}{d t}$

$\frac{\partial T}{\partial t}+u_{r} \frac{\partial T}{\partial r}=\left(\frac{k}{\rho_{\ell} c_{p}}\right)\left[\frac{1}{r^{2}} \frac{\partial}{\partial r}\left(r^{2} \frac{\partial T}{\partial r}\right)\right]$ 
with the following initial and boundary conditions

$$
\begin{aligned}
& T(r, 0)=T_{e} \\
& T\left(R_{a}, t\right)=T_{e} \\
& \frac{d T}{d r}(R, t)=\frac{\rho_{v} h_{f g}}{k_{\ell}} \frac{d R}{d t}
\end{aligned}
$$

The conservation equations and associated boundary conditions were solved by using the Galerkin finite element method. The computational domain was discretized with isoparametric and quadratic triangular elements. To solve the moving interface problem, the Arbitrary Lagrangian-Eulerian method (ALE) was implemented. The solution method was verified by comparing the numerical result against the well-known analytical solution given by Mikic et al. (1970).

A small temperature disturbance at the bubble interface was used to initiate the bubble growth. Then, the momentum equation was solved for a given liquid superheat by using the fourth-order Runge-Kutta method to calculate the new values of $R$ and $d R / d t$. Next, the heat flux at the interface was calculated from the boundary condition, which is the energy balance at the bubble interface, Eq. (7). Later, the thermal diffusion equation, Eq. (4), was solved to calculate a new interface temperature. The above sequence was repeated until convergence on $d R / d t$ at a given time step. The calculations were repeated until the bubble completely blocked the artery.

Figure 6 shows typical results obtained with a liquid superheat of $3 \mathrm{~K}$ at four different operating temperatures: $\mathrm{T}_{\mathrm{e}}=249,269$ and $289 \mathrm{~K}$. An initial bubble size of $100 \mu \mathrm{m}$ was assumed. As the bubble radius was nondimensionalized with the artery radius, at $R / R_{a}=1$, the bubble blocks the artery. The bubble growth rate rapidly increased with decreasing evaporator temperature. As it is very difficult to measure the amount of superheat in the evaporator, the results were obtained at an expected superheat of $3 \mathrm{~K}$. Increasing the superheat quickly increased the bubble growth rate. For higher superheat values, the bubble can block the artery almost instantaneously. These results clearly demonstrate the need for venting pores in the evaporator section. Without the venting pores, an evaporator dryout is inevitable.

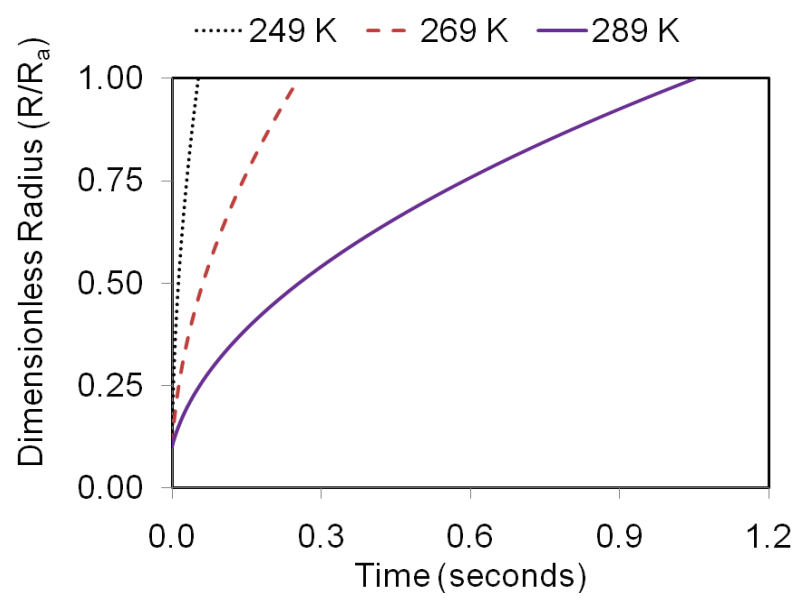

Fig. 6 Bubble growth time at different evaporator temperatures.

\subsection{Venting Pore Optimization}

The two important design parameters for this heat pipe are the size of an individual venting pore and the distance separating the two consequent pores. For the former, the venting pore radius sets the capillary pressure across artery mesh since it is the largest pore. Using a small pore radius to maintain a high capillary pressure is however risky since a small pore may not allow the meniscus coalescence to work properly. Therefore, the pore size needs to be optimized. For the latter, if the distance between two consequent pores is too large, the arterial priming may be unnecessarily delayed. However, if they are positioned too close, an excessive pressure drop will result. The problem is highly complex. In the following section, the optimization of the venting pore size and separation distance was explained by using two separate models.

\subsubsection{Optimization of the venting pore size}

For the glazing problem previously explained, Eninger (1974) proposed an effective solution. As shown in Fig. 7, a small pore on the arterial mesh can help coalescing the menisci on the opposite sides of the pore.
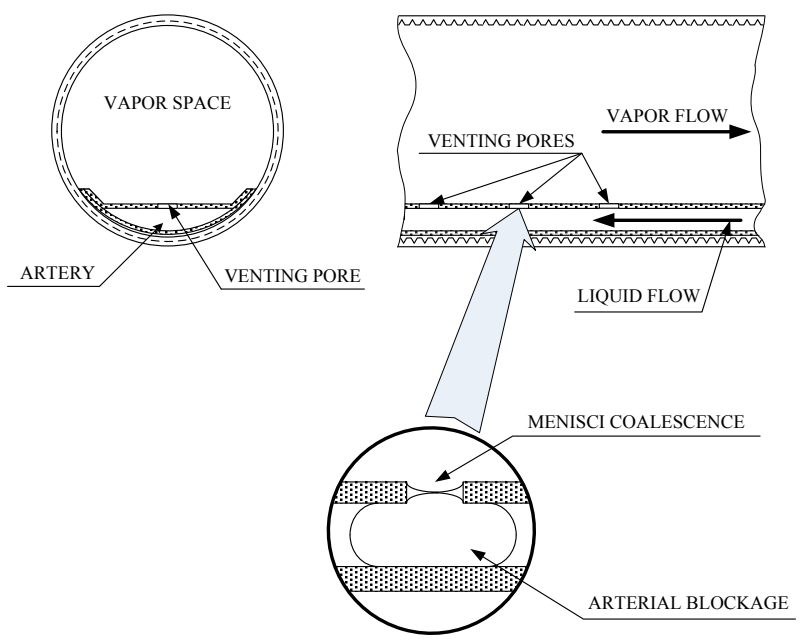

Fig. 7 Meniscus coalescence technique (Not to scale).

The pore size is directly related to the mesh thickness. From the geometrical considerations and pressure balance of a blocked artery, it is possible to calculate a critical venting pore diameter as a function of the liquid-vapor pressure difference and the artery mesh thickness. Starting from the Eninger's work, an equation for the venting pore diameter was derived as follows

$D_{p} \geq \sqrt{\frac{\tau h}{\cos \theta}\left(2-\frac{\tau \cos \theta}{h}\right)}$

In driving the above equation, the limiting liquid-vapor pressure difference required for priming the artery was used as the venting criterion. In Eninger (1974), a more conservative approach was suggested, which assumes the liquid-vapor pressure difference corresponding to a flooded venting pore as the venting criterion. This leads to a slightly larger venting pore diameter for a given foil thickness and is thus more conservative from the meniscus coalescence point of view. Using Eq. (8), for the heat pipe presented in this work, the radius of the venting pores was set to $0.254 \mathrm{~mm}$.

In addition, the pores can hinder the arterial priming by reducing the priming force on the inside perimeter of the artery. A single row of venting pores presents an optimum pattern to minimize the number of breaks in the perimeter at a given axial location. As a result, the venting pores were lined up in a single row along the artery mesh.

\subsubsection{Optimization of the venting pore separation distance}

The venting pores by altering the arterial cross section introduce a pressure drop along the heat pipe. A smaller number of venting pores is 
therefore desirable. To minimize this pressure drop, the pores were placed only in the most critical region, namely the evaporator section. To calculate an optimum distance between the venting pores, a simplified mathematical model was developed. The segmented artery of the heat pipe was represented by a circular cross-section with the equivalent hydraulic radius of $0.98 \mathrm{~mm}$. The model geometry is shown in Fig. 8, where an arterial section is represented with a vapor blockage in the middle. The main goal of this model is to predict the speed of the moving liquid-vapor interface and consequently to find an optimum distance between venting pores in a way that an arterial blockage is quickly cleared.

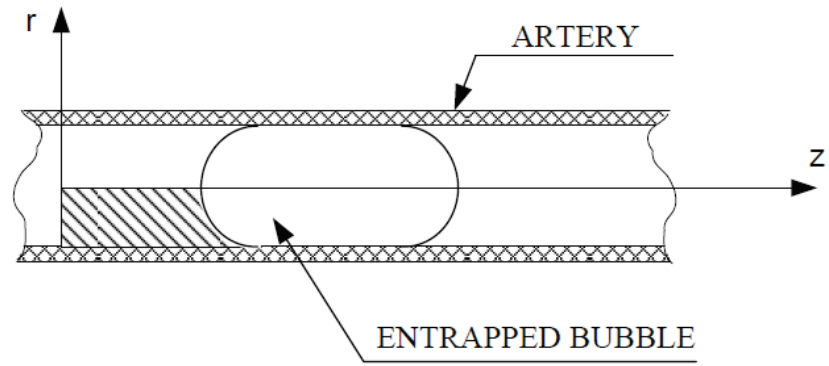

Fig. 8 Model geometry for the optimization of the pore separation distance (Not to scale).

We assume that the interface motion is mainly controlled by heat transfer and therefore ignore the momentum transfer across the interface. This assumption is well justified for low superheat values and away from the early stages of bubble growth. Because of the symmetry, only the shaded region in Fig. 8 was considered.

The problem is axially symmetric and the governing equation takes the following form

$\frac{\partial T}{\partial t}=\frac{k}{\rho_{\ell} c_{p}}\left[\frac{1}{r} \frac{\partial}{\partial r}\left(r \frac{\partial T}{\partial r}\right)+\frac{\partial^{2} T}{\partial z^{2}}\right]$

At $t=0$, the temperature of liquid in the entire domain was set to a prescribed value, $T_{\text {init }}$

A simplified set of boundary conditions were used. The symmetry condition was imposed at $r=0$.

$\frac{\partial T}{\partial r}(0, z)=0$

A uniform heat flux was prescribed at $r=R_{a}$.

$-k \frac{\partial T}{\partial r}\left(R_{a}, z\right)=q_{a}$

The temperature at $z=0$ was assumed to be equal to the initial liquid temperature.

$T(r, 0)=T_{\text {init }}$

Considering that the liquid was superheated in the artery, the liquid-vapor interface temperature was assigned to a value as a function of a prescribed superheat, $T_{i n}=T_{\text {init }}-\Delta T$.

The governing equation and associated boundary conditions were solved by using the previously described finite element method, where an ALE method was employed to deal with the moving interface problem. The vapor-liquid interface was moved using the following thermal balance equation at the interface $u_{n}=-\frac{k}{\rho_{\ell} h_{f g}} \frac{\partial T}{\partial n}$

The typical results for $T_{\text {init }}=303 \mathrm{~K}$ and a superheat of $3 \mathrm{~K}$ at heat loads of $Q=60,80$ and $120 \mathrm{~W}$ are shown in Fig. 9, where the interface displacement at the arterial mesh wall is plotted as a function of time.

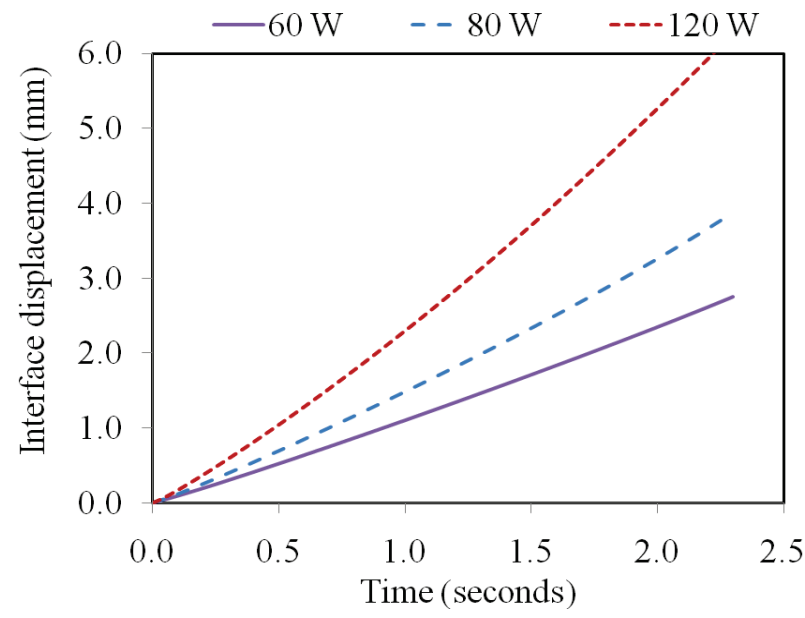

Fig. 9 Interface displacement at different heat loads.

The speed of interface progress increased with the increasing heat load as expected. These results indicated that once the artery was blocked, the liquid-vapor interface progress was not very fast. This must be due to the low thermal diffusivity of ammonia. Based on these results, it can be suggested that the distance separating the subsequent venting pores should be very small to minimize the arterial obstruction time. Not surprisingly, the worst case occurs when the interface is located in the middle of two subsequent pores. By arbitrarily assigning one second for the time required to prime the artery, the distance should be on the order of $2.2 \mathrm{~mm}$ for the case of $Q=60 \mathrm{~W}$. The speed increased with the amount of superheat but these results were not significantly different from the results presented on Fig. 9; therefore, they are not shown on this figure. As a result, a superheat of $3 \mathrm{~K}$ can be considered a conservative value. Taking also into account manufacturing considerations, the optimum distance between the centers of the subsequent pores was chosen to be $2.0 \mathrm{~mm}$. This distance should minimize the arterial reprime time without unnecessarily increasing the pressure drop in the artery.

\section{CONCLUSIONS}

The numerical and analytical methods used in this work successfully described several significant thermal performance characteristics of the VCAHP. It was shown that the NCG-supported bubbles were quickly absorbed in the condenser at the expected operating temperatures. The bubble collapse times increased with decreasing sink temperatures. However, the bubbles formed in the evaporator section grew very quickly due to the heat addition. This growth rate was increased very rapidly with increasing liquid superheat. The numerical results indicated that the arterial blockage is inevitable even at low superheats without the presence of the venting pores.

The diameter of the venting pores and the distance between them are crucial design parameters for the successful operation of this heat pipe. An analytical method was used to calculate an optimum venting pore diameter. The pores were arranged in a single row to reduce the pressure drop. To further minimize the pressure drop introduced by the pores, the maximum distance between subsequent pores was calculated by taking into account the speed of the liquid-vapor interface movement. 
Tests were conducted to verify both the heat transfer limit and variable conductance operation. Experimental results demonstrated the ability of the VCAHP to vent a potential arterial blockage by the NCGsupported bubbles. The VCAHP presented in this work can be used for applications demanding high heat loads and precise temperature control. The flexible transport sections and multiple bends can also be incorporated to satisfy demanding thermal requirements.

\section{NOMENCLATURE}

\begin{tabular}{ll}
$c_{p}$ & specific heat at constant pressure $\left(\mathrm{J} \mathrm{kg}^{-1} \mathrm{~K}^{-1}\right)$ \\
$D_{p}$ & venting pore diameter $(\mathrm{m})$ \\
$h$ & artery height $(\mathrm{m})$ \\
$h_{f g}$ & latent heat of evaporation $\left(\mathrm{J} \mathrm{kg}^{-1}\right)$ \\
$k$ & thermal conductivity $\left(\mathrm{W} \mathrm{m}^{-1} \mathrm{~K}^{-1}\right)$ \\
$P$ & pressure $(\mathrm{Pa})$ \\
$q$ & heat flux $\left(\mathrm{W} \mathrm{m} \mathrm{m}^{-2}\right)$ \\
$Q$ & applied heat load $(\mathrm{W})$ \\
$r$ & radial coordinate $(\mathrm{m})$ \\
$R$ & bubble radius $(\mathrm{m})$ \\
$R_{a}$ & artery radius $(\mathrm{m})$ \\
$T$ & temperature $(\mathrm{K})$ \\
$t$ & time (s) \\
$u$ & velocity (m s$\left.)^{-1}\right)$ \\
$z$ & axial coordinate $(\mathrm{m})$ \\
Greek symbols & \\
$\Delta T$ & superheat $(\mathrm{K})$ \\
$\theta$ & wetting angle (rad) \\
$\mu$ & viscosity $(\mathrm{Pa} \mathrm{s})$ \\
$\rho$ & density (kg m $\left.{ }^{-3}\right)$ \\
$\sigma$ & liquid-vapor surface tension $\left(\mathrm{N} \mathrm{m}^{-1}\right)$ \\
$\tau$ & artery mesh thickness (m) \\
Subscripts & \\
$a$ & artery \\
$c$ & condenser \\
$e$ & evaporator \\
in & interface \\
init & initial \\
$\ell$ & liquid \\
$n$ & normal component \\
sat & saturation \\
$v$ & vapor \\
& \\
\hline &
\end{tabular}

\section{REFERENCES}

Abhat, A., Groll, M., Hage, M., 1975, "Investigation of Bubble Formation in Arteries of Gas-Controlled Heat Pipes," AIAA-1975-655, $10^{\text {th }}$ Thermophysics Conference, Denver, CO.

Alario, J. P., Haslett, R., Kosson, R., 1981, “The Monogroove High Performance Heat Pipe," AIAA-1981-1156, $16^{\text {th }}$ Thermophysics Conference, Palo Alto, CA.

Ambrose, J., and Holmes, H. R., 1991, "Development of the Graded Groove High Performance Heat Pipe," AIAA-1991-0366, 29th Aerospace Sciences Meeting, Reno, NV.

Antoniuk, D., and Edwards, D. K., 1980, "Depriming of Arterial Heat Pipes: an Investigation of CTS Thermal Excursions," NASA-CR165153.

Blinchevskii, I. M., Aptekar, B. F., Baum, Y. M., 1983, (in Russian), Prom. Teplotekh, 5(6), 26-29.
Bryan, J. E., and Seyed-Yagoobi, J., 1997, "Heat Transport Enhancement of Monogroove Heat Pipe with Electrohydrodynamic Pumping," Journal of Thermophysics and Heat Transfer, 11, 454-460. doi: $10.2514 / 2.6261$

Eninger, J. E., 1974, "Menisci Coalescence as a Mechanism for Venting Noncondensable Gas from Heat-Pipe Arteries," AIAA-1974-748, Thermophysics and Heat Transfer Conference, Boston, MA.

Faghri, A., 1995, Heat Pipe Science and Technology, Taylor \& Francis, Washington DC.

Goncharov, K. A., Orlov, A. A., Kolesnikov, V. A., Kochetkov, A. A., 2000, "Arterial Heat Pipes in Russian Spacecraft," Proc. 4th Minsk International Seminar on Heat Pipes, Heat Pumps, Refrigerators, Minsk.

Goncharov, K. A., Kochetkov, A. Y., Antonov, V. A., 2006, "Development of the Low Temperature Arterial Heat Pipes," SAE 2006-01-2223, 36th International Conference on Environmental Systems (ICES), Norfolk, VA.

Holmes, H. R., and Field, A. R., 1986, "The Gas-Tolerant HighCapacity Tapered Artery Heat Pipe," AIAA-1986-1343, 4th Joint Thermophysics and Heat Transfer Conference, Boston, MA.

Kaya, T., 2009, "Analysis of Vapor-gas Bubbles in a Single Artery Heat Pipe," International Journal of Heat and Mass Transfer, 52, 57315739 .

doi:10.1016/j.ijheatmasstransfer.2009.08.015

Kosson, R., and Swerdling, B., 1975, "Self-filling Hollow Core Arterial Heat Pipe," US Patent No. 3901311.

Kosson, R., Brown, R., Ungar, E. K., 1990, "Space Station Heat Pipe Advanced Radiator Element (SHARE) Flight Test Results And Analysis," AIAA-1990-0059, 28th Aerospace Sciences Meeting, Reno, NV.

Maziuk V., 2005, “Arterial Miniature Heat Pipes,” Proc. 6th Minsk International Seminar on Heat Pipes, Heat Pumps, Refrigerators, Minsk.

McIntosh, R., Knowles, G., Hembach, R. J., 1972, "Sounding Rocket Heat Pipe Experiment," AIAA-1972-259, $7^{\text {th }}$ Thermophysics Conference, San Antonio, TX.

McIntosh, R., Ollendorf, S., Harwell, W., 1975, “The International Heat Pipe Experiment," AIAA-1975-726, $10^{\text {th }}$ Thermophysics Conference, Denver, CO.

Mikic, B. B., Rohsenow, W. M., Griffith, P., 1970, "On Bubble Growth Rates," International Journal of Heat and Mass Transfer, 13 (4), 657666.

Mock, P. R., Marcus, D. B., Edelman, E. A., 1975, "Communications Technology Satellite: a Variable Conductance Heat Pipe Application," Journal of Spacecraft and Rockets, 12(12), 750-753.

doi:10.2514/3.57044

Ponnappan, R., Beam, J.E., Mahefkey, E.T., 1986, "Priming and Flow Visualization in the Double Wall Artery Heat Pipe," Proceedings of $8^{\text {th }}$ International Heat Transfer Conference, San Francisco, CA.

Ponnappan, R., Ramalingam, M. L., Johnson, J. E., Mahefkey, E.T., 1988, "Analysis of Evaporator Critical Heat Flux in the Double Wall 
Artery Heat Pipe.” AIAA-1988-356, 26th Aerospace Sciences Meeting, Reno, NV.

Saaski, E. W., 1972, "Investigation of Bubbles in Arterial Heat Pipes," NASA-CR-114531.

Schlitt, R., 1997, "Evolution of Heat Pipe Technology for Satellite Application," $10^{\text {th }}$ International Heat Pipe Conference, Stuttgart, Germany.

Streckert, L., and Ambrose, J., 2009, "Steady State Performance Results for a Flexible High-Performance Variable Conductance Heat
Pipe," SAE 2009-01-2502, 39th International Conference on Environmental Systems (ICES), Savannah, GA.

Supper, W., and Groll, M., 1985, "Heat Pipe Tests on Space Shuttle Flights," SAE 851356, 15th International Conference on Environmental Systems (ICES), San Francisco, CA.

Wanous, D. J., Marcus, B. D., Kirkpatrick, J. P., 1975, "A Variable Conductance Heat Pipe Flight Experiment: Performance in Space," AIAA-1975-725, 10 $0^{\text {th }}$ Thermophysics Conference, Denver, CO 